\title{
Proximal Aortic Dissection with Rupture into the Main Pulmonary Artery-A Case Report
}

\author{
Ramachandran Muthiah \\ Thoothukudi Medical College Hospital, Thoothukudi, India \\ Email: cardioramachandran@yahoo.co.uk
}

How to cite this paper: Muthiah, R. (2017) Proximal Aortic Dissection with Rupture into the Main Pulmonary Artery-A Case Report. Case Reports in Clinical Medicine, 6, 64-88.

https://doi.org/10.4236/crcm.2017.63007

Received: February 9, 2017

Accepted: March 28, 2017

Published: March 31, 2017

Copyright $\odot 2017$ by author and Scientific Research Publishing Inc. This work is licensed under the Creative Commons Attribution International License (CC BY 4.0).

http://creativecommons.org/licenses/by/4.0/

\section{c) (7) Open Access}

\begin{abstract}
Aim: To present a rare occurrence of aortopulmonary fistula due to rupture of proximal aortic dissection in a 48-year-old woman. Introduction: Aortic dissection is defined as disruption of the medial layer provoked by intramural bleeding, resulting in separation of aortic wall layers and subsequent formation of a true lumen and a false lumen with or without communication. Case Report: A 48-year-old female presented with vague anterior chest discomfort, high blood pressure, systolic-diastolic murmur in the left sternal border with ECG changes of myocardial ischemia. Echocardiography revealed a dilated aortic root with intimal flaps, a leak into the pulmonary artery and regional hypokinesis with contractile dysfunction suggesting a proximal aortic dissection with rupture into the main pulmonary artery. Discussion: The etiology of aortic dissection was mostly hypertension in $80 \%$ of cases and aortopathies such as connective tissue disorders, inflammatory and idiopathic. Aortic wall stress is a major trigger of intimal tear and two-dimensional transthoracic echocardiography is an excellent, initial diagnostic gold standard to detect the dissecting flaps, especially in proximal aortic dissection. Conclusion: Blood pressure control is the mainstay of treatment and urgent surgery is indicated in proximal aortic dissection since there is higher chance of rupture with an increase in mortality.
\end{abstract}

\section{Keywords}

Dilated Aortic Root, Intimal Flap, Aortic Insufficiency, Aortic Rupture, Aortopulmonary Fistula

\section{Introduction}

The aorta is a large elastic artery composed of three layers; the thin delicate intimal layer is lined by endothelium and can be easily traumatized; the thick middle layer is the media, composed of sheets of spirally arranged elastic tissue which 
affords maximum tensile strength, smooth muscle cells and collagen. Adventitia is the outer layer composed of loose connective tissue and carries vasa vasorum which nourishes the outer half of the aortic wall including much of the media. The ascending aorta is $5 \mathrm{~cm}$ long and its lower segment; the aortic root is $3.3 \mathrm{~cm}$, begins at the level of the aortic valve, extends to the sinotubular junction and the upper tubular segment joins with the aortic arch. Aorta may be considered as dilated if the diameter is $>40 \mathrm{~mm}$ at the level of ascending aorta, $35 \mathrm{~mm}$ at the arch and thoracic descending aorta, and $30 \mathrm{~mm}$ at abdominal aorta. Aortic root dilatation predisposes to the dissection or rupture which accounts for $1 \%-2 \%$ of deaths in industrialized nations [1]. The maximal internal diameter of ascending aorta in dissection is $55.7 \pm 12.4 \mathrm{~mm}$ (range $35-90 \mathrm{~mm}$ ). Aortic dissection is not always associated with aneurysmal dilatation of aortic root [2]. The dissection may originate from an area of non-dilated aorta even in Marfan's syndrome, especially in children [3] as a result of abnormal vascular extracellular matrix protein, the fibrillin [4] due to mutation in fibrillin-1 gene [5] and also in a spectrum of overlapping diseases such as Goldberg syndrome, familial or isolated forms of aortic aneurysm, "Mass" phenotype which are collectively called as "Type-1 fibrillinopathies" [6] or structural defects in the pro $\alpha$-1 (III) of type III collagen in Ehler-Danlos syndrome (EDS) type IV (EDS vascular type). Mutation in other genes such as COL3A1 gene [7] is also reported in these connective tissue disorders.

Cystic medial necrosis (smooth muscle cell necrosis and elastic fiber degeneration with the presence of cystic spaces filled with mucoid material in the media) associated with connective tissue disorders was once believed to contribute to degeneration of the aortic media leading to aortic dissection most frequently in the ascending aorta (first few $\mathrm{cms}$ of ascending aorta and $90 \%$ found within $10 \mathrm{~cm}$ of aortic valve). Degenerative changes associated with aging result in breakdown of collagen, elastin, smooth muscle cell as well as an increase in basophilic ground substance contributing the histologic change of cystic medial necrosis associated with dissection. However, a study showed that a minority of patients with aortic dissection established medial degeneration [8]. Sometimes, these changes lead to weakening of the aortic wall and results in formation of fusiform aneurysm often involving the aortic root. The term annuloaortic ectasia was used to describe this condition which was first coined by Ellis et al. in 1961, occurs in $5 \%$ to $10 \%$ of patients with aortic regurgitation and the aortic root is bulbous, pear-shaped as shown in Figure 1, pyriform appearance or flask shaped. In syphilis, the spirochetes directly infect the aortic media during the second phase of the disease, most commonly involving the ascending aorta after a latent period of 5 - 40 years, destroy the muscular and elastic elements of the media and the inflammatory response is replaced by fibrous tissue that frequently calcifies. The medial destruction often results in progressive aneurysmal dilatation of the aortic root, only potentially causes aortic dissection in tertiary stage [9] and it has become a rarity today [10] as a result of aggressive antibiotic treatment at its early stage. Thus, aortic diseases such as aortic dilatation, aortic aneurysm, 


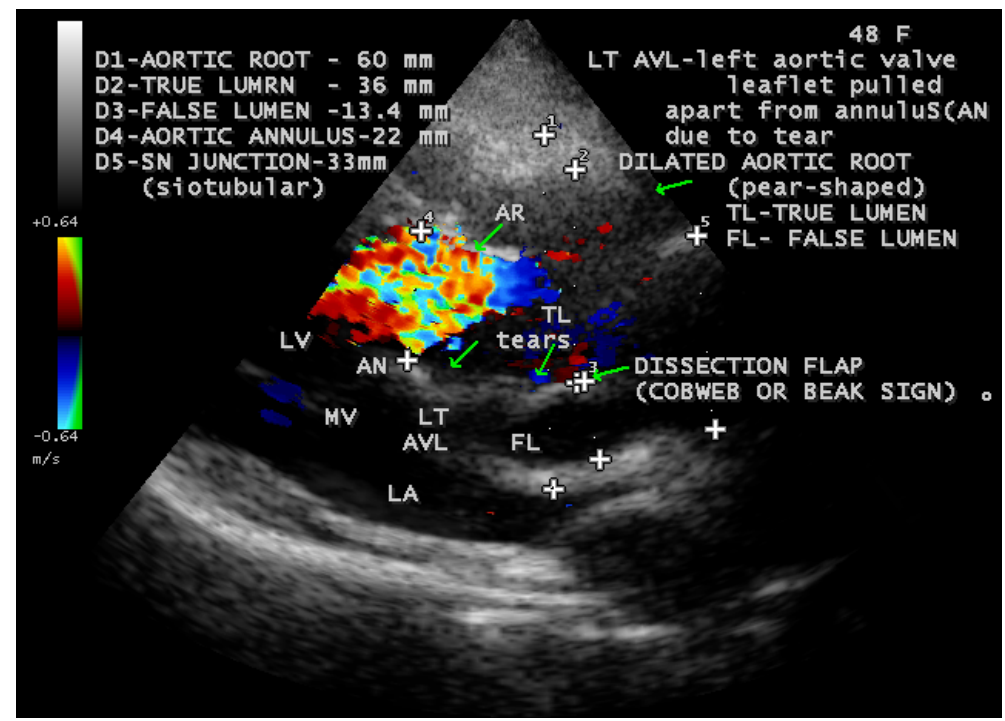

Figure 1. Parasternal long axis view showing the leak into the LVOT (left ventricular outflow tract) as aortic regurgitation due to rupture at the site of annular support of the aortic valve.

annuloaortic ectasia, chromosomal aberrations (eg. Turner syndrome, Noonan syndrome), aortic arch hypoplasia, coarctation of the aorta, aortic arteritis, bicuspid aortic valve and hereditary connective tissue disorders (Marfan's syndromemajority of dissection is $<40$ years of age, EhlersDanlos syndrome) are well-established predisposing factors for the development of aortic dissection [11] [12]. Marfan's syndrome significantly shows fragmentation and degeneration of elastin and helical collagen fibers with defective biosynthesis and cross-linkage of collagen substance [13]. The contributing risk factors for aortic dissection [14] are shown in Table 1.

Mechanical forces contributing to aortic dissection include flexion forces at fixed sites, radial impact of pressure pulse, and the shear stress of the blood. Aortic dissection occurs in the region of aorta that is subjected to the greatest $\mathrm{d} P / \mathrm{d} t$ (the rate of increase in pressure or the LV ejection force) and pressure fluctuation [15]. The hydrodynamic forces in the blood stream that are generated by the propagation of a pulse wave with a velocity increases from $4-5 \mathrm{~m} / \mathrm{s}$ in the ascending aorta to $5-6 \mathrm{~m} / \mathrm{s}$ in the abdominal aorta [16] and systolic BP during each cardiac cycle deliver kinetic energy to the aortic wall and the repeated motion of aorta related to contractile function of the heart results in flexion stress which are more marked in the ascending aorta and eventually leads to dissection and its propagation. Hypertension is one of the most significant triggers for aortic dissection in $72 \%-90 \%$ of cases [17] and tends to be higher in distal dissections (70\%) than proximal dissections (36\%). Hypertension adds to a mechanical strain and the shearing forces exerting a longitudinal stress along the aortic wall contributing to the development of aortic dissection. Severe hypertension is relatively common during the period of hospitalization after an acute aortic dissection even without a prior history of hypertension and it may reflects marked increase in sympathetic tone, triggered by severe inflammation of aortic wall due 
Table 1. Risk factors for aortic dissection.

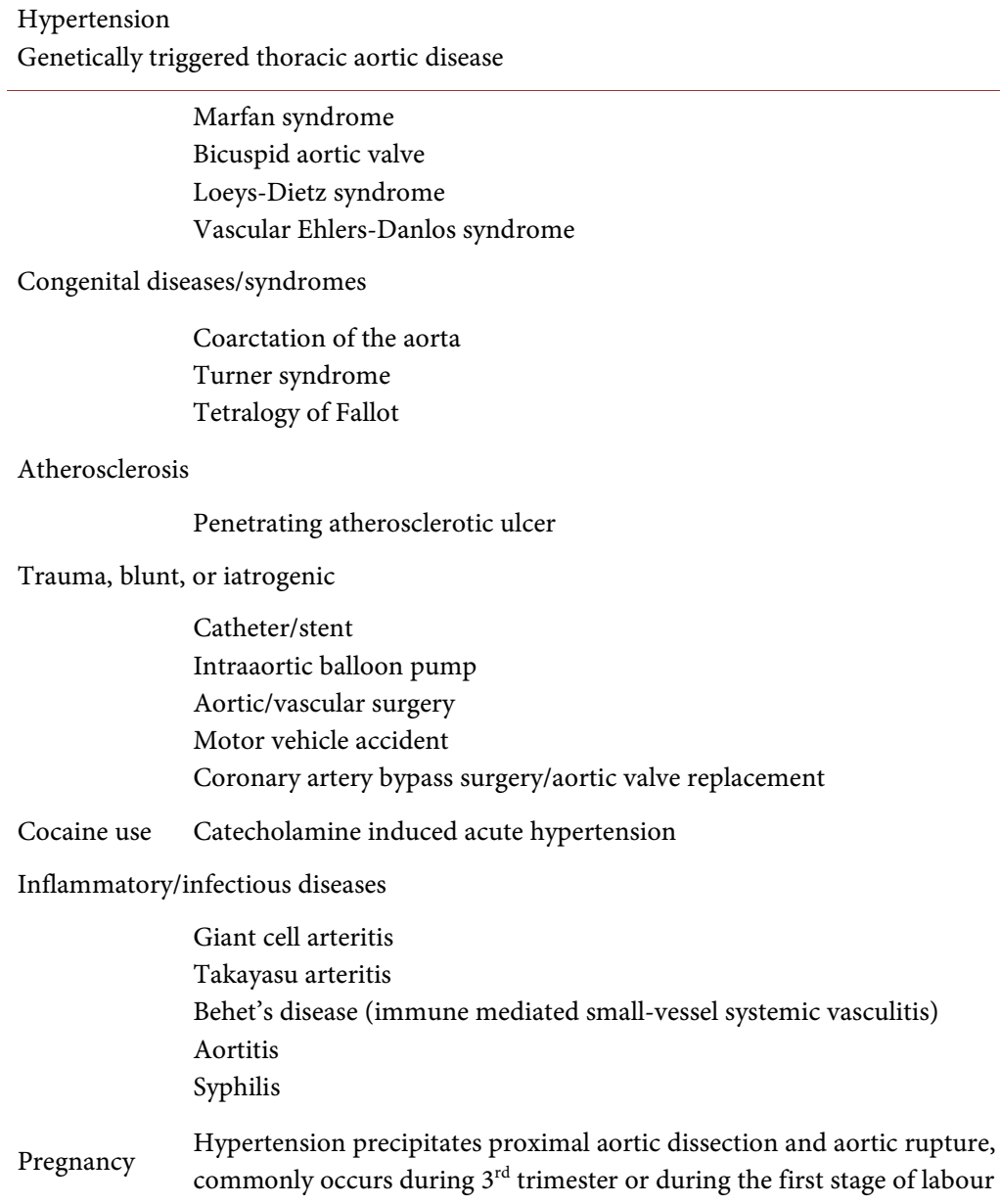

to dissection process rather than renal ischemia. Weightlifting is known to elicit profound hemodynamic stress on the wall of the aorta [18] and may predispose the younger persons to aortic dissection, particularly type I.

Classification systems are used to locate the aortic dissection and its extent. The Stanford classification was developed from a functional approach based on whether the ascending aorta was involved as shown in Table 2. Dr. Michael DeBakey, a pioneer in vascular surgery developed a classification as shown in Table 3. Many cases of aortic dissection do not fit into these classifications since a dissection limited to aortic arch, proximal to left subclavian artery but not involving ascending aorta may not be classified as type A or type B. Therefore, it is prudent to simplify the classification into anatomical categories, the proximal aortic dissection refers to involvement of aorta proximal to the origin of left subclavian artery which may or may not extend distally and distal aortic dissection refers to the involvement of aorta distal to the origin of left subclavian artery. In 1999, a classification based on the pathophysiologic features of aortic lesion rather than its location by the European Society of cardiology [19] was shown in Table 4. Some authors state that type A dissections are confined proximal to brachiocephalic artery and type B dissections are confined distal to it. 
Table 2. Stanford classification [20].

\begin{tabular}{|c|c|c|}
\hline Type A & \multicolumn{2}{|c|}{$\begin{array}{l}\text { Dissection involves the ascending aorta and/or aortic arch, and possibly the } \\
\text { descending aorta. The tear can originate in the ascending aorta, the aortic arch, } \\
\text { or more rarely, in the descending aorta. It includes DeBakey types I and II }\end{array}$} \\
\hline Type B & \multicolumn{2}{|c|}{$\begin{array}{l}\text { Involves the descending aorta or the arch (distal to the left subclavian artery), } \\
\text { without the involvement of the ascending aorta. It includes DeBakey type III }\end{array}$} \\
\hline Table 3. DeB & akey cla & fication-an anatomical description of aortic dissection [21]. \\
\hline \multicolumn{2}{|l|}{ Type $1(68 \%)$} & $\begin{array}{l}\text { Originates in ascending aorta and propagates at least to the aortic arch } \\
\text { and often beyond it distally. It is most often seen in patients less than } \\
65 \text { years of age and is the most lethal form of the disease }\end{array}$ \\
\hline \multicolumn{2}{|c|}{ Type II (10\% - 15\%) } & Originates in the ascending aorta and is confined to it \\
\hline \multicolumn{2}{|c|}{ Type III (25\% - 30\%) } & $\begin{array}{l}\text { Originates in the descending aorta and rarely extends proximally, } \\
\text { but will extend distally. It most often occurs in elderly patients with } \\
\text { atherosclerosis and hypertension }\end{array}$ \\
\hline \multicolumn{2}{|l|}{ Type IIIa } & Propagates proximally or distally, mostly above the diaphragm \\
\hline \multicolumn{2}{|l|}{ Type IIIb } & Propagates distally to the abdominal aorta \\
\hline
\end{tabular}

Table 4. Pathophysiological-ESC (European Society of Cardiology) classification.

$\begin{array}{cl}\text { Class } 1 & \text { Classical aortic dissection with an intimal flap between true and false lumen } \\ \text { Class } 2 & \text { Medial disruption with formation of Intramural haematoma/haemorrhage } \\ \text { Class } 3 & \text { Discrete/subtle dissection without haematoma, eccentric bulge at tear site } \\ \text { Class } 4 & \begin{array}{l}\text { Plaque rupture leading to aortic ulceration, penetrating aortic atherosclerotic } \\ \text { ulcer with surrounding haematoma, usually subadventitial }\end{array} \\ \text { Class } 5 & \text { Iatrogenic and traumatic dissection }\end{array}$

Thus, it is recommended that acute aortic syndrome (AAS) are classified according to both lesion type and location [22].

A leak or rupture of the dissection process into the surrounding structures is rapidly fatal and so this case had been reported.

\section{Case Report}

A 48-year-old, hypertensive woman was admitted with sudden onset of palpitations and chest discomfort for 3 days duration. She skipped the antihypertensive medications for one week and experienced pain over the anterior chest without any migratory character or radiation and the pain was a vague discomfort rather than sharp and knife like. The pulse rate was $115 \mathrm{bpm}$ and blood pressure 200/130 $\mathrm{mmHg}$ and no pulse or BP differentials in the extremities. General examination revealed no features of Marfan's syndrome. Physical examination revealed basal crackles over the lung fields and cardiac auscultation revealed "to-and-fro" systolic-diastolic murmur over the left second and third intercostal spaces mimicking grade 3/6 continuous murmur. Blood chemistry revealed normal. ECG revealed sinus tachycardia with ischemic changes as $\mathrm{T}$-wave inversions in left precordial leads as shown in Figure 2. X-ray chest revealed normal as shown in 


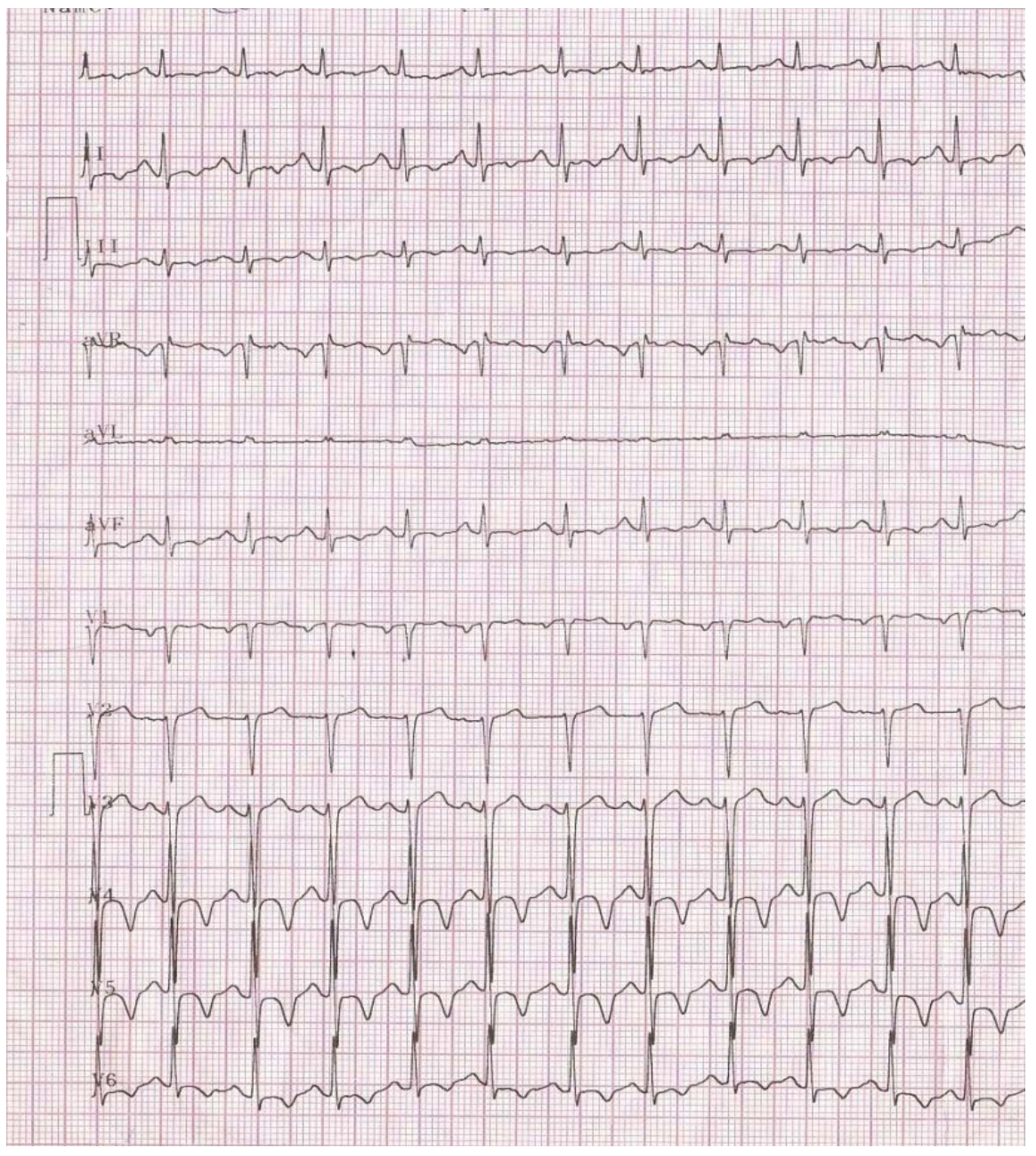

Figure 2. ECG showing sinus tachycardia and ischemic changes as T-wave inversion in left precordial leads.

Figure 3. Emergency transthoracic 2D echocardiography revealed a dilated aortic root with a fibrosed intimal flap in the infero-medial aspect as shown in Figure 4, suggesting a chronic proximal aortic dissection and the aortic cusp was displaced from the annulus due to the tear of dissection. Another dissection flap was found in the supero-medial aspect of the aortic root as shown in Figure 5. A regurgitation jet in the LVOT (left ventricular outflow tract) as in Figure 1 and a leak into the pulmonary artery as shown in Figure 6 and Figure 7 suggesting an aortic rupture with fistulation into the main pulmonary artery (aotopulmonary fistula). The patient was treated with IV nitroglycerin, labetalol $100 \mathrm{mg}$ twice daily and diuretics. She was stabilised with medical therapy and planned for surgical correction, preferably Bentall's procedure with closure of the fistula, but died suddenly following a syncopal episode when begin to ambulant.

\section{Discussion}

\subsection{Review of Literature}

The first case of aortic dissection was reported by Frank Nicholls in an autopsy 


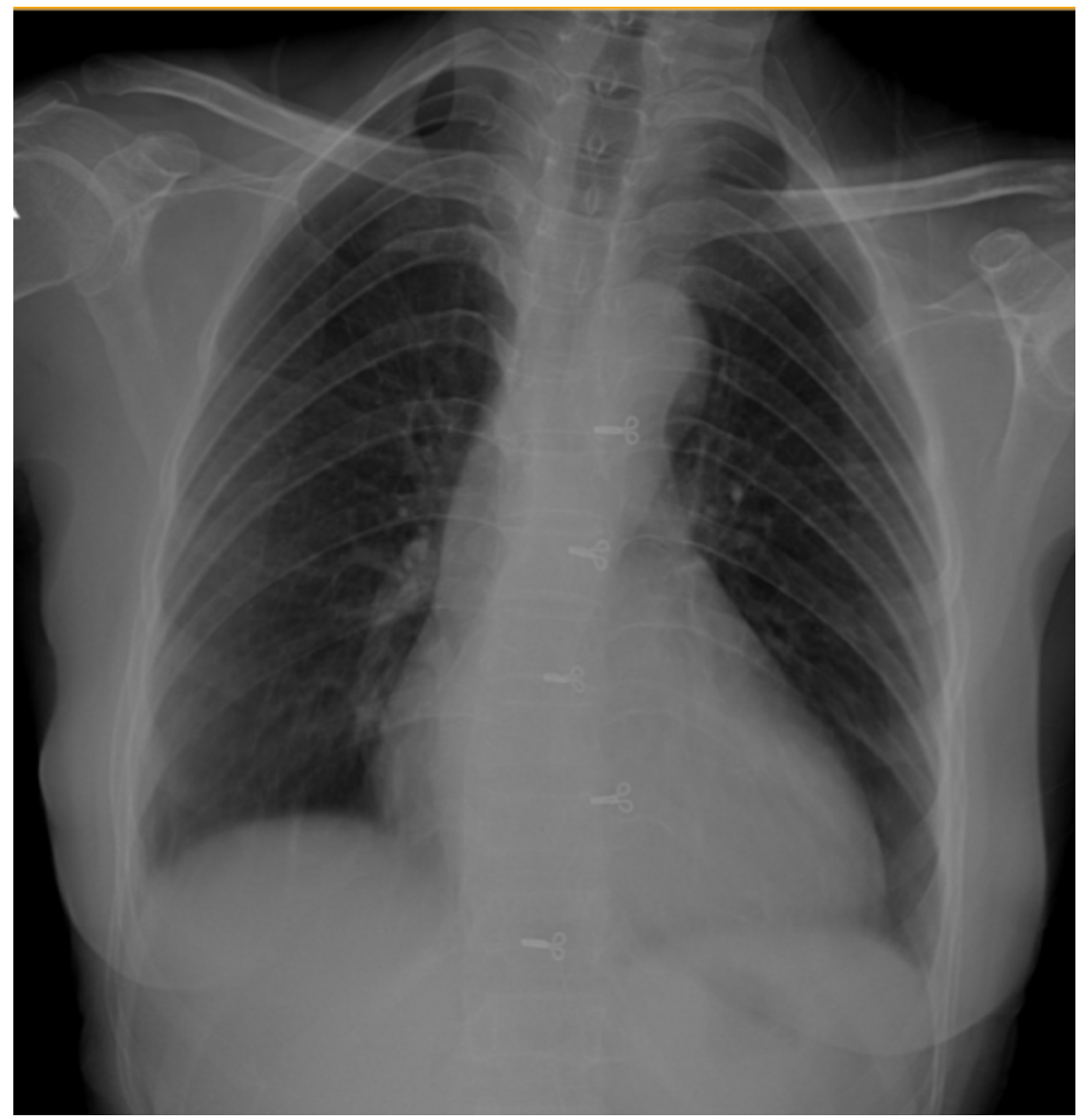

Figure 3. X-ray chest PA (postero-anterior) view-normal.

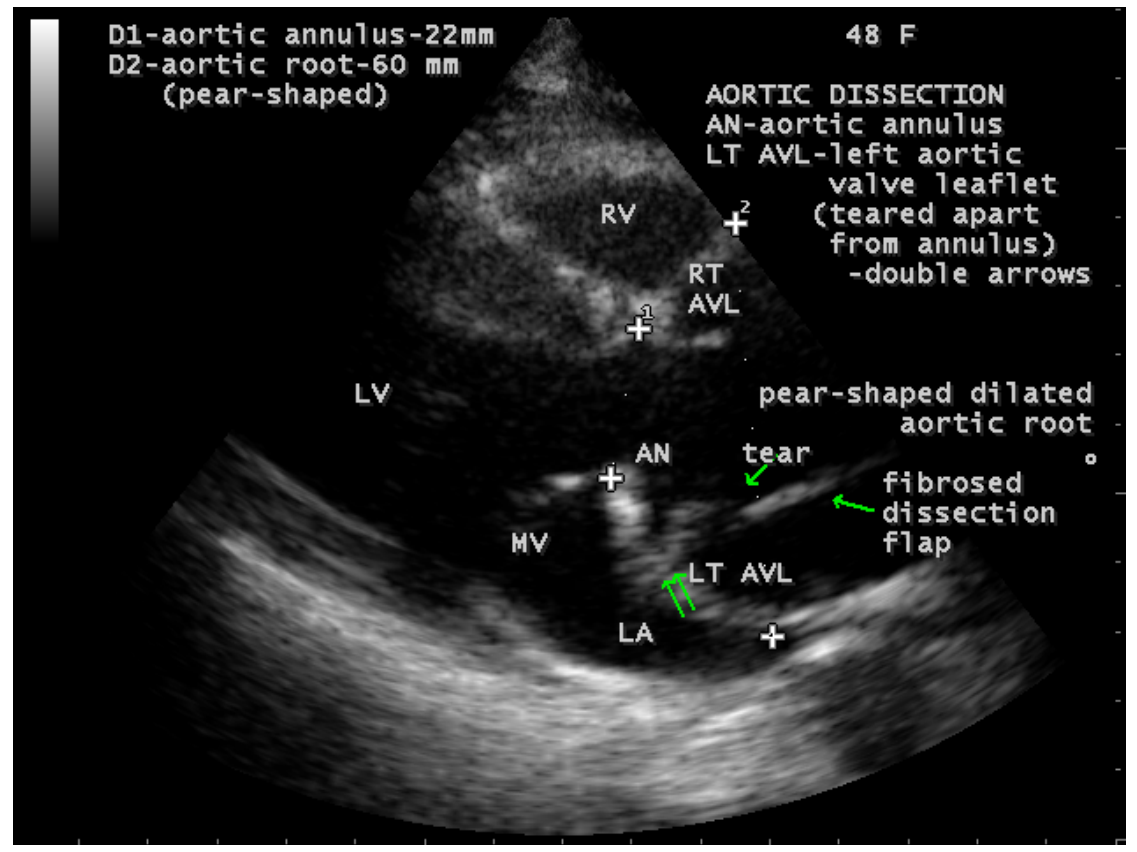

Figure 4. Parasternal long axis view showing the fibrosed dissection flap (intimal flap) in the infero-medial aspect of the aortic root, tear in the flap with displaced left aortic valve leaflet (LT AVL) teared from the annulus (AN) (double arrows). The dilated aortic root is pear-shaped. 


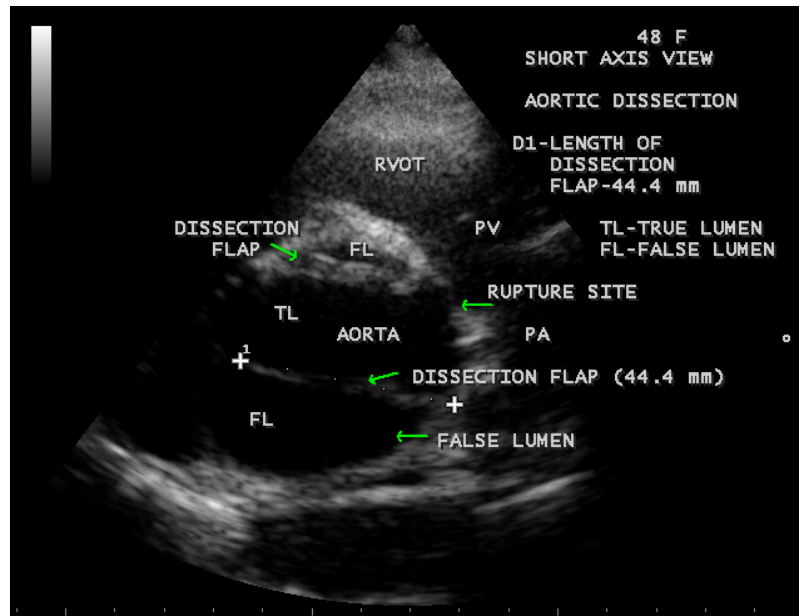

Figure 5. Short axis view showing the intimal flap, site of rupture into the pulmonary artery and a second dissection flap at the supero-medial aspect of aortic root.

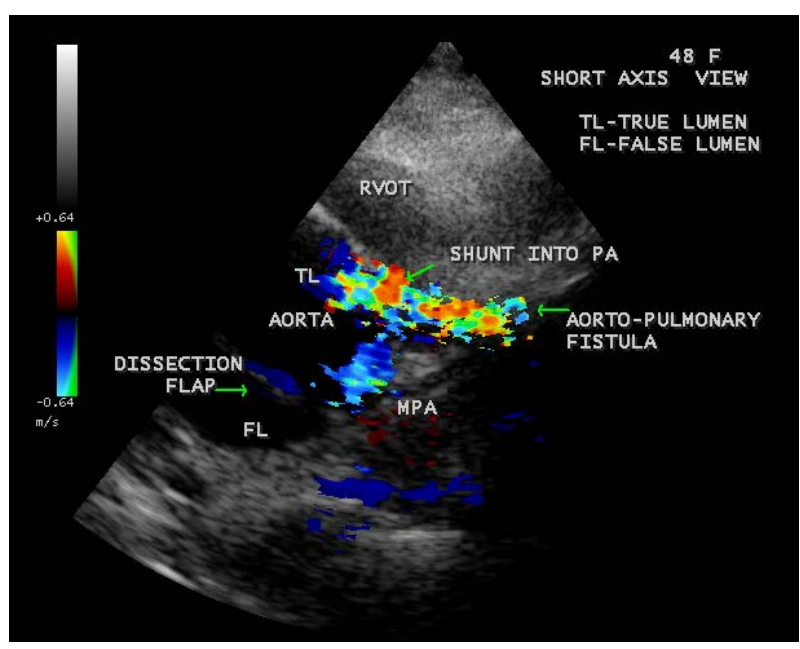

Figure 6. Short axis view showing the progression of leak into the pulmonary artery. MPA-main pulmonary artery.

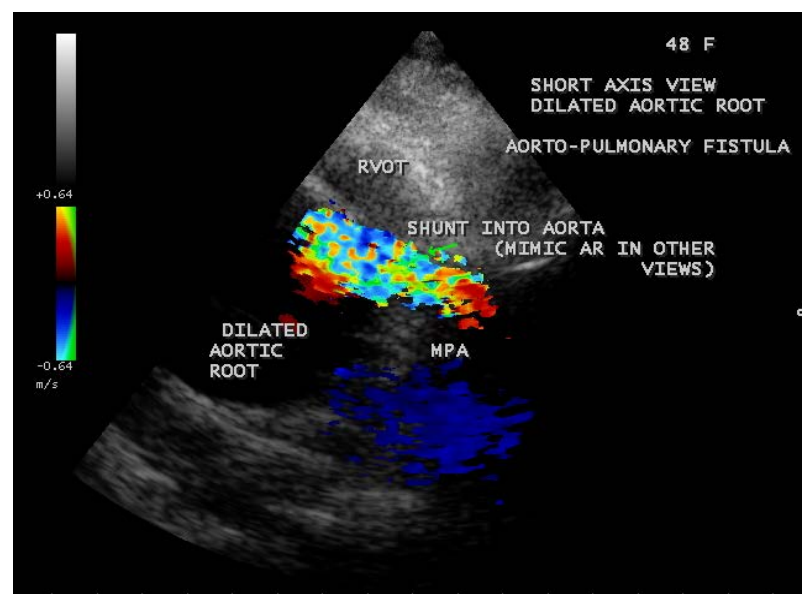

Figure 7. Short axis view showing the aortopulmonary fistula. MPA-main pulmonary artery. Mimicking aortic regurgitation in other views such as in Figure 1 and Figure 8. 
report of King George II of Great Britain who died suddenly while straining in a toilet [23] on 25 October, 1760 and found a dissection in the aortic arch which ruptured into the pericardium [24] [25]. J. P. Maunoir, a French physician introduced the term "aortic dissection" in 1802. Thomas Bevill Peacock, a London cardiologist reported two series as 19 cases in 1843 and 80 cases in 1863 in the literature [26]. In 1924, Boyd reviewed 4000 autopsy reports of thoracic aortic aneurysms, finding 1197 cases of rupture with a $4 \%$ occurrence of aortopulmonary fistula [27]. In 1970, Bory and associates first reported an aortopulmonary fistula in a young woman [28]. In 1972, McCarthy and associates described an acute aortic dissection spreading through the ductus arteriosus to the pulmonary artery [29]. In 1995, Spier and Associates [30] described a unique case of rupture into both right ventricle and pulmonary artery with good outcome. In 1998, Atay and associates [31] reported a case of aortopulmonary fistula in a 73-year-old man. In 1999, a fistula was found between the false lumen and main pulmonary artery in a man underwent surgery for type A aortic dissection [32].

\subsection{Pathophysiology}

Aorta plays an important role in modulating left ventricular performance and arterial function throughout the entire cardiovascular system [33]. An increase in distending pressure during systole induces an increase in aortic dimension, which is directly related to the elastic properties of aorta. Aorta expands at a rate of $0.9 \mathrm{~mm}$ in men and $0.7 \mathrm{~mm}$ in women for each decade of life and a diameter larger than $6 \mathrm{~cm}$ are definitely more prone to rupture than smaller ones [34]. The ascending part of the aorta bears the largest pressure during the cardiac cycle [35] and its exposure to elevated pressures causes a tear in the intimal lining at the sites of greatest wall stress and results in dissection which propagates either anterograde or retrograde directions along the arterial wall. This entrance tear is the initiating event and blood enters into the media and splits the aortic lumen to form a double-channel aorta with a true and false lumen. The intima and the inner part of the media form the intimomedial flap which separates the false lumen from the true lumen and is composed mainly of aortic media delaminated from the aortic wall [36]. When blood flows into the false lumen, it may cause secondary tears in intima, blood can reenter the true lumen and creating additional communication between the true and false lumens in the distal aorta. The true lumen is usually small with high-velocity flow whereas the false lumen is larger with slower velocity and turtbulent flow.

In autopsy series, as many as $13 \%$ of aortic dissections do not have an identifiable intimal tear [37]. In a minority of cases, the initiating event is the medial hemorrhage due to rupture of vasa vasorum. The intramural hematoma weakens the aortic wall and may progress either to outward rupture of the aortic wall in $35 \%$ of cases or to inward disruption of the intima, leading to communicating dissection in $3 \%$ to $5 \%$ of cases [38]. In penetrating aortic ulcer, an atheromatous plaque burrowing deeply through the intima into the media [39], the media is exposed to pulsatile arterial flow, which causes hemorrhage into the walls that 
then leads to intramural hematoma [40] and adventitial erosion may cause rupture in $42 \%$ of cases [41]. These nonflap lesions are more common in the descending aorta especially in elderly hypertensive individuals [42]. Spontaneous resolution of an aortic intramural hematoma also has been reported [43]. The noncommunicating dissection is characterized by no entry tear and no flow in the false lumen, the false lumen is more often filled with thrombus and the differentiation from intramural hematoma may be difficult [44]. In the Japanese Guidelines for thoracic aortic dissection 2011, it is defined the non-communicating dissection as no communication between the false lumen and true lumen [45].

\subsection{Clinical Perspectives}

Von Kodolitsch et al. [46] identified the independent predictors of aortic dissection in a study of 200 patients. Aortic dissection is also classified according to its duration, defined as length of time from symptom onset to medical evaluation as acute ( $<2$ weeks), subacute $(>2$ weeks and chronic ( $>6$ weeks after the onset of pain)). The characteristic symptom of tearing pain in the chest was recognized in 1855 when a case was diagnosed in life. Pain is the most common symptom of acute aortic dissection in $96 \%$ of cases and those without pain are found to have chronic dissection [47]. The pain could be sharp (64\%), tearing or ripping type (51\%) or knife-like and its abruptness is the most specific characteristic feature. Pain is severe, unbearable at its inception and forces the patient to writhe in agony, fall to the ground or pace restlessly in an attempt to gain relief and has a tendency to migrate along the path of dissection in $17 \%$ of cases. The pain was located in anterior chest in $>90 \%$ of cases of ascending aortic dissection, in interscapular area (36\%) and back (53\%) in descending thoracic aortic dissection, in abdomen and lower extremities (30\%) when the dissection extending distally into the abdominal aorta. The initial pain of aortic dissection may be followed by a pain-free interval lasting from hours to days and then pain returns, is an ominous sign of impending rupture [48]. About $4 \%$ of acute dissections may be painless especially in diabetes and older individuals, making a delay in diagnosis [49]. Pulse deficits were reported in $<20 \%$ of patients with aortic dissection $(50 \%$ in proximal and $15 \%$ in distal dissections). It includes a significant difference in pulse volume (pulse differentials) and blood pressure (BP differentials) in two upper extremities due to partial compression of one or both subclavian arteries or a sudden loss of pulse with abrupt onset of chest pain raise a high suspicion of aortic dissection. The difference of $>20 \mathrm{mmHg}$ of systolic blood pressure may be found in $10 \%$ to $20 \%$ of unaffected individuals [50]. The presence of pulse differential is the most specific physical sign of aortic dissection in $38 \%$ of cases, may be transient, secondary to decompression of the false lumen by distal reentry into the true lumen or secondary to the movement of the intimal flap away from the occluded orifice. When a false lumen communicates with the true lumen, the duplication of pulse due to difference in flow rates in the true and false channels occurs and it is a rare physical finding of aortic dissection [51].

Myocardial infarction occurs in $1 \%-2 \%$ of cases of aortic dissection second- 
ary to the compression of coronary artery by the expansion of false lumen or the extension of dissection process. Involvement of right coronary artery is more common than the left one and, occasionally dissection and myocardial infarction occur concomitantly [52].

Aortic regurgitation accompanies in $18 \%$ to $50 \%$ of cases of proximal aortic dissection [53]. The mechanisms include dilatation of aortic root, annular dilatation, tearing of annulus or valve cusps, rupture of the annular support of the leaflets as shown in Figure 8, cusp prolapse due to pressure from asymmetric false lumen and physical interference of valve closure by intimal flap (intimal flap prolapse). In Marfan's syndrome, the aortic dilatation is confined to sinuses, effacement of sinotubular junction (failure to narrow at sinotubular junction) results in malcoaptation of leaflets and subsequent aortic regurgitation [54].

The risk of fatal rupture in patients with untreated proximal aortic (the aortic root and ascending portion) dissection is around $90 \%$, and $70 \%$ of ruptures occur into pericardium, pleural cavity and mediastinum [55] leading to cardiac tamponade, left sided pleural effusion, hypotension and shock. Rare cases have been described in which the dissection eroded into the pulmonary artery and producing aorto-pulmonary fistula as in Figure 7 [56]. It is important to rule out the presence of pseudohypotension due to obstruction of an aortic arch branch in aortoarteritis.

Raised concentrations of smooth muscle myosin heavy chain (a protein that released from damaged aortic medial smooth muscle) at higher levels (51 \pm 52.3 $\mu \mathrm{g} / \mathrm{L})$ within 3 hours of symptoms) than in acute myocardial infarction $(2.1 \pm$ $1.6 \mu \mathrm{g} / \mathrm{L})$ occurs in aortic dissection [57] and it is elevated $(>2.5 \mu \mathrm{g} / \mathrm{L})$ from the normal level $(0.9 \pm 0.4 \mu \mathrm{g} / \mathrm{L})$ in healthy individuals within 6 hours of the onset of dissection. It may become a useful initial step in triaging the patients with suspected aortic dissection provided that the patients present within 6 hours and

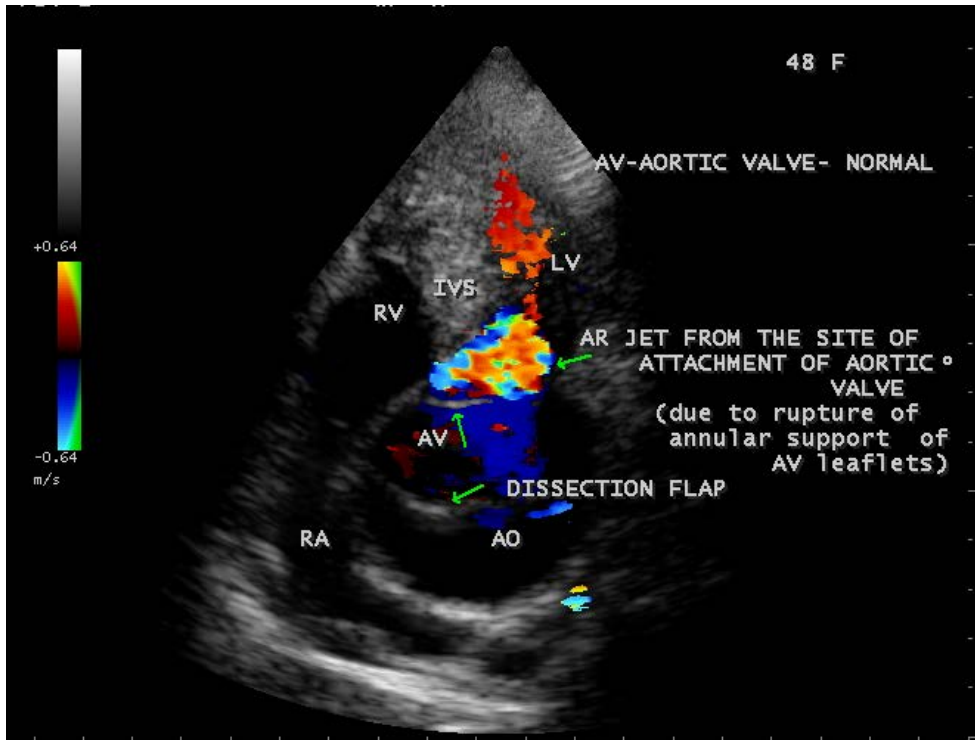

Figure 8. Apical view showing the leak into the LVOT (left ventricular outflow tract) from the site of rupture with normally attached aortic valve. 
preferably within 3 hours. Its level is higher in proximal dissection than the distal and levels $>10 \mu \mathrm{g} / \mathrm{L}$ shows $100 \%$ specificity for aortic dissection within $30 \mathrm{mi}$ nutes of the assay. A blood D-dimer level $<500 \mathrm{ng} / \mathrm{ml}$ may rule out aortic dissection [58], but the AHA (American Heart Association) is not advising this test as evidence is still tentative [59].

Radiologically, mediastinal widening (bulge to the right with ascending dissection and to the left with descending dissection), localized hump on the aortic arch with widening of aortic knob distal to left subclavian artery and the separation of intimal calcification from the outer aortic soft tissue border by $10 \mathrm{~mm}$, a finding on chest X-ray is called as "calcium sign" are the characteristic features of aortic dissection. About $12 \%$ to $20 \%$ of aortic dissections had normal chest $\mathrm{X}$-rays as shown in Figure 3.

It is important to prevent misdiagnosis of thoracic aortic dissection. About $20 \%$ of patients with type A dissection had ECG evidence of acute ischemia or acute myocardial infarction [60] and erroneous administration of thrombolytic therapy may be unavoidable and hazardous. A compilation of reminders, symptoms, and risk factors called as Ritter rules (named for the actor John Ritter who died due to thoracic aortic dissection in September 11, 2003 which was misdiagnosed and treated as acute myocardial infarction) was formulated to predict the aortic dissection [61]. Aortopulmonary fistula should be suspected in a patient who had aneurysmal dilatation of aortic root and exhibits signs of heart failure.

\subsection{Echocardiographic Features}

Two-dimensional echocardiography is currently considered as the first noninvasive technique when aortic dissection is clinically suspected in an emergency room [62] and it has a sensitivity of $78 \%$ to $100 \%$ to diagnose type A dissection [63]. A dissection may extends weeks to months after its onset [64] and the tear is defined as a disruption of the flap continuity as shown in Figure 4 with fluttering of the ruptured intimal borders [65]. The visualization of an intimal flap that separates the true and false lumens within the aorta is pathognomonic of aortic dissection [66] as shown in Figure 4 and Figure 5. The two-dimensional echocardiography appears to be superior [67] in the recognition of an intimal flap and its utility is limited in visualization of a small circumscript dissection segment in the distal part of ascending aorta and anterior part of the arch, known as "blind spot" due to interposition of trachea and left main stem bronchus between the esophagus and the aortic arch. Two echocardiographic criteria for the diagnosis of aortic dissection are:

a) Dilatation of one segment of the aorta.

b) An abnormal linear intraluminal echo corresponding to the intimal flap [68] [69].

There are 3 types of intimal flap were identified as shown in Table 5.

In some cases, a linear echo criss-crossing or dividing the aorta perpendicularly is highly diagnostic of an intimal flap as shown in short axis image in Figure 5. If a thrombus is detected, the intimal flap is immobile and an aortic wall 
thickness $>15 \mathrm{~mm}$ suggests dissection with thrombus in the false lumen. The intimal tear is usually $>5 \mathrm{~mm}$, located at the level of ascending aorta in $60 \%$ to $65 \%$ of cases and this segment is more prone to rupture. The oscillating intimo-intimal flap always indicate an acute dissection without thrombosis of false lumen [70] and a parallel wall motion with absence of oscillating flap indicates a chronic dissection [71]. The intimal flap, an anatomical marker of identifying the false lumen may appear as "cobweb" or "beak" appearance as shown in Figure 1 and Figure 9 [72]. In acute dissection, the false lumen is more often larger and it is smaller in chronic dissections. The intimal flap is usually thick, may be calcified, less mobile and fibrosed in chronic dissection as shown in Figure 4 and Figure 9. In rare instances, fistulous formation between the aorta and pulmonary artery may complicate dissection due to rupture as shown in Figure 6, Figure 7, Figure 10, and Figure 11. A disturbed diastolic flow signal was detected in the left ventricular outflow tract as aortic regurgitation as in Figure 1, Figure 8 and Figure 12 due to tear of annular support of leaflets at the site of rupture and this leak between aorta and pulmonary artery creating an acquired aortopulmonary fistula in this patient as shown in Figure 6 and Figure 7.

Table 5. Types of intimal flap [73].

\begin{tabular}{ll}
\hline Type 1 & $\begin{array}{l}\text { Long }(>1 \mathrm{~cm}) \text {, thin, bright, mobile in the lumen and undulating, vibrating or waving } \\
\text { with a sail-like motion in M-mode recording (long oscillating flap) }\end{array}$ \\
Type 2 & $\begin{array}{l}\text { A long but minimally mobile linear echo which was duplicated and parallel to one } \\
\text { or two aortic walls. }\end{array}$ \\
Type 3 & $\begin{array}{l}\text { A short, double linear image with a rapid systolic motion and high frequency } \\
\text { oscillations }\end{array}$
\end{tabular}

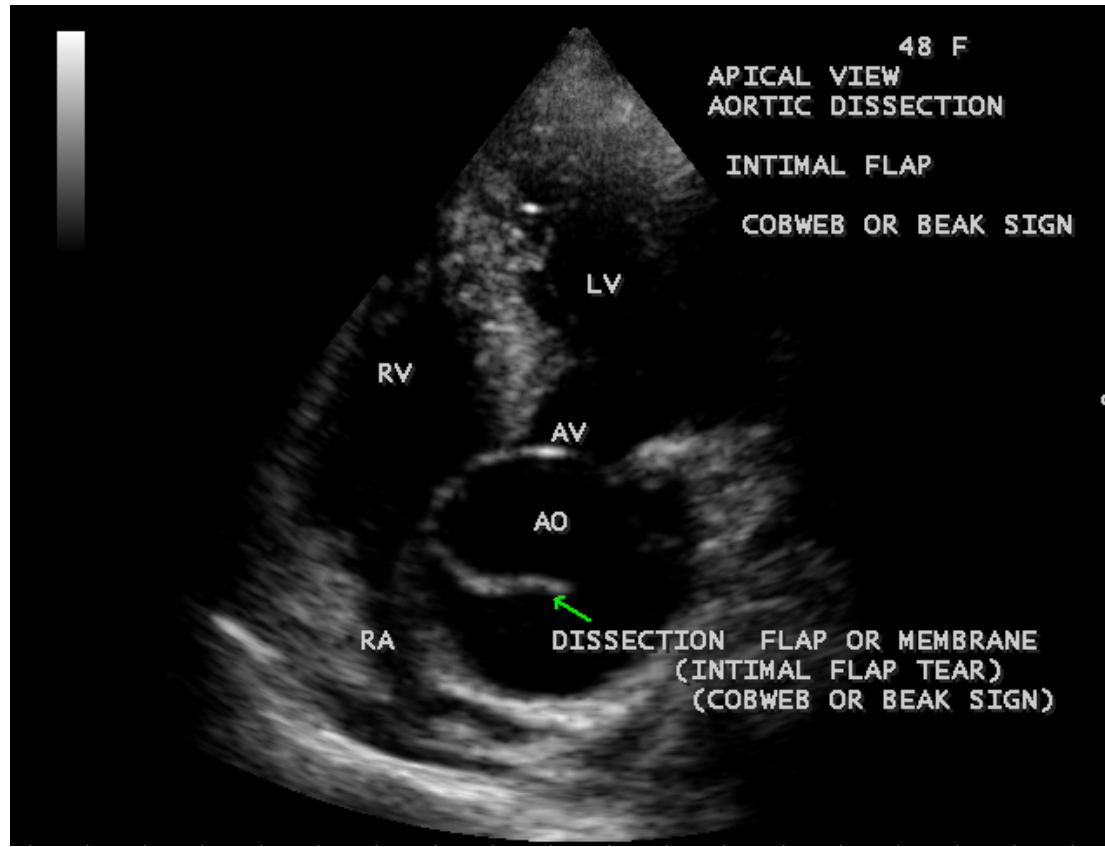

Figure 9. Apical view showing the dilated aortic root, normal aortic valve and dissecting membrane with a beak appearance. 


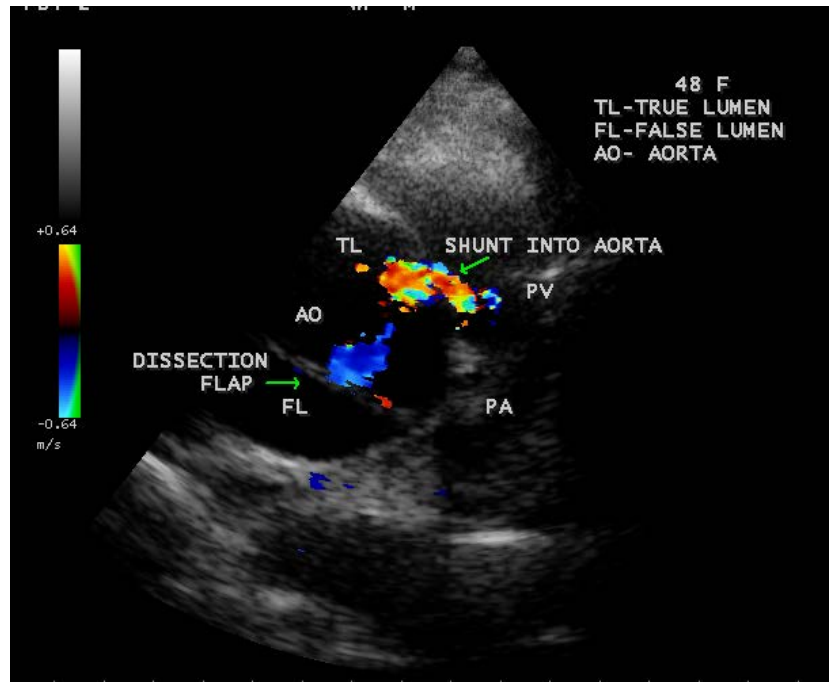

Figure 10. Short axis view showing the leak into the aorta from the ruptured site.

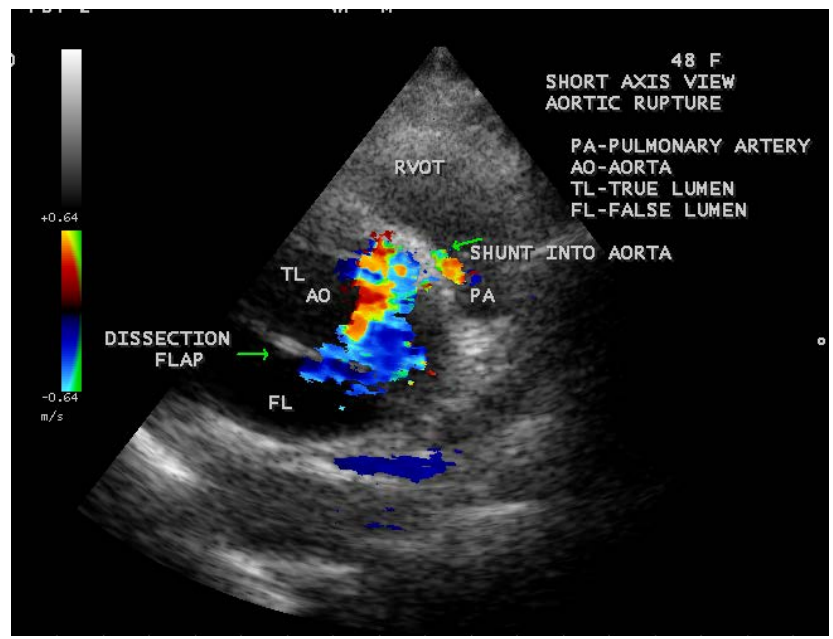

Figure 11. Short axis view showing the progression of leak into the aorta.

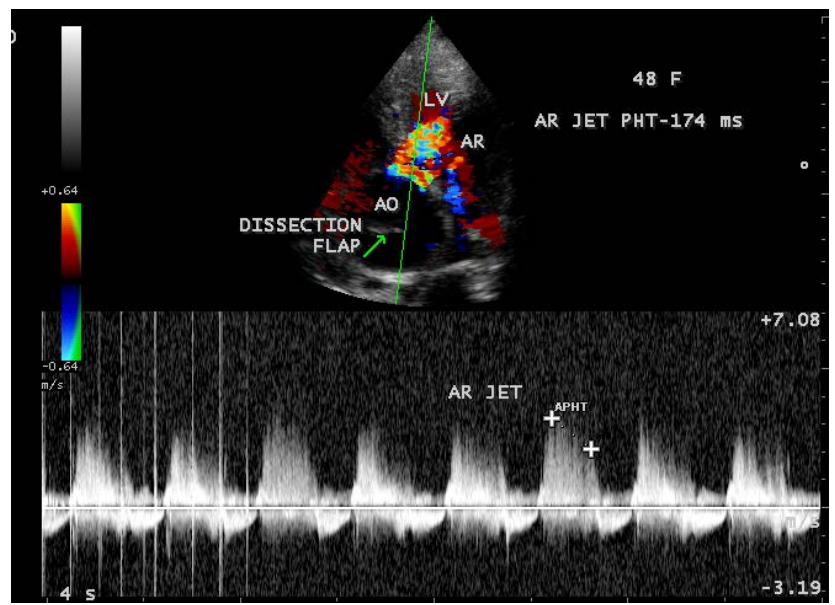

Figure 12. CW (continuous wave) Doppler showing the leak jet mimicking as aortic regurgitation (AR). 
A dilated pear-shaped aortic root as in Figure 1 and Figure 4 with regional wall motion abnormalities, particularly the inferior hypokinesis as shown in Figure 13 due to right coronary occlusion is suggestive of acute type A aortic dissection with a dissection flap and small false lumen in the supero-medial aspect of the aortic root as in Figure 5 in the short axis image in an already existing chronic disease as in Figure 4, leading to contractile dysfunction (EF 40\%) as shown in Figure 13. The aortic arch and descending aorta appeared normal as shown in Figure 14.

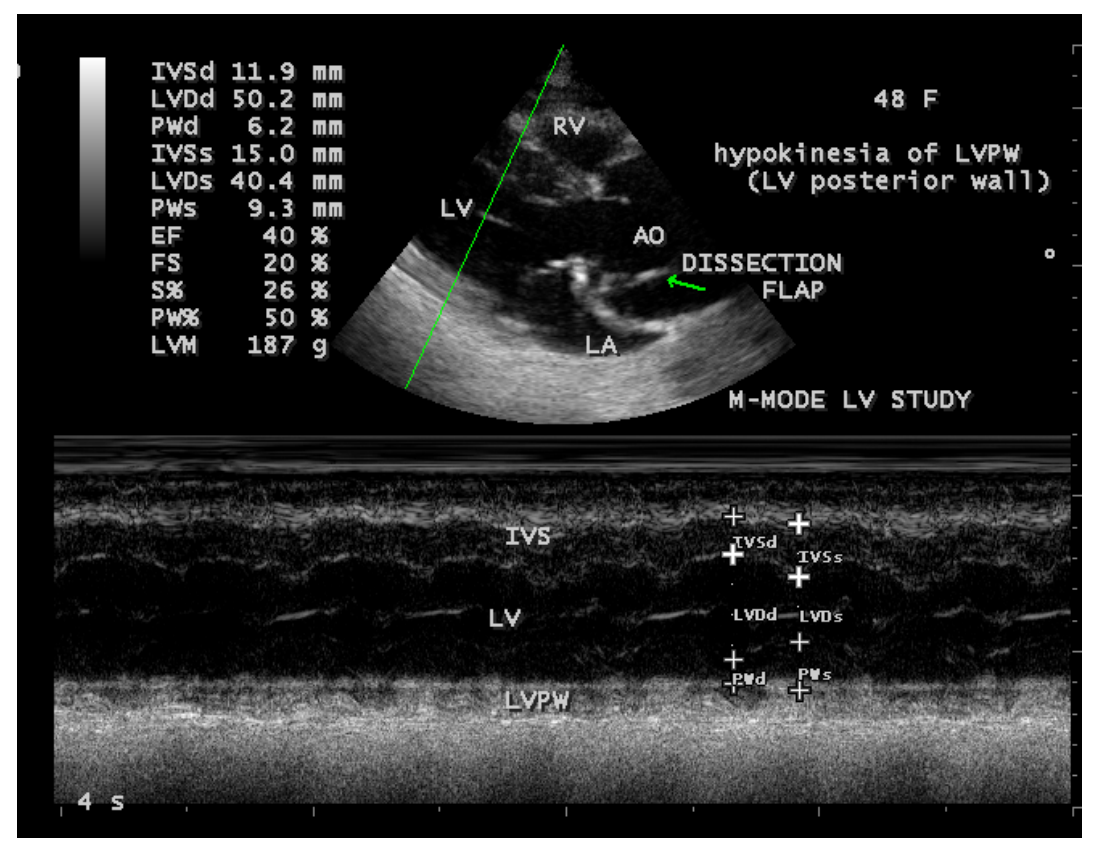

Figure 13. M-mode LV study showing the inferior wall hypokinesis with contractile dysfunction (EF 40\%).

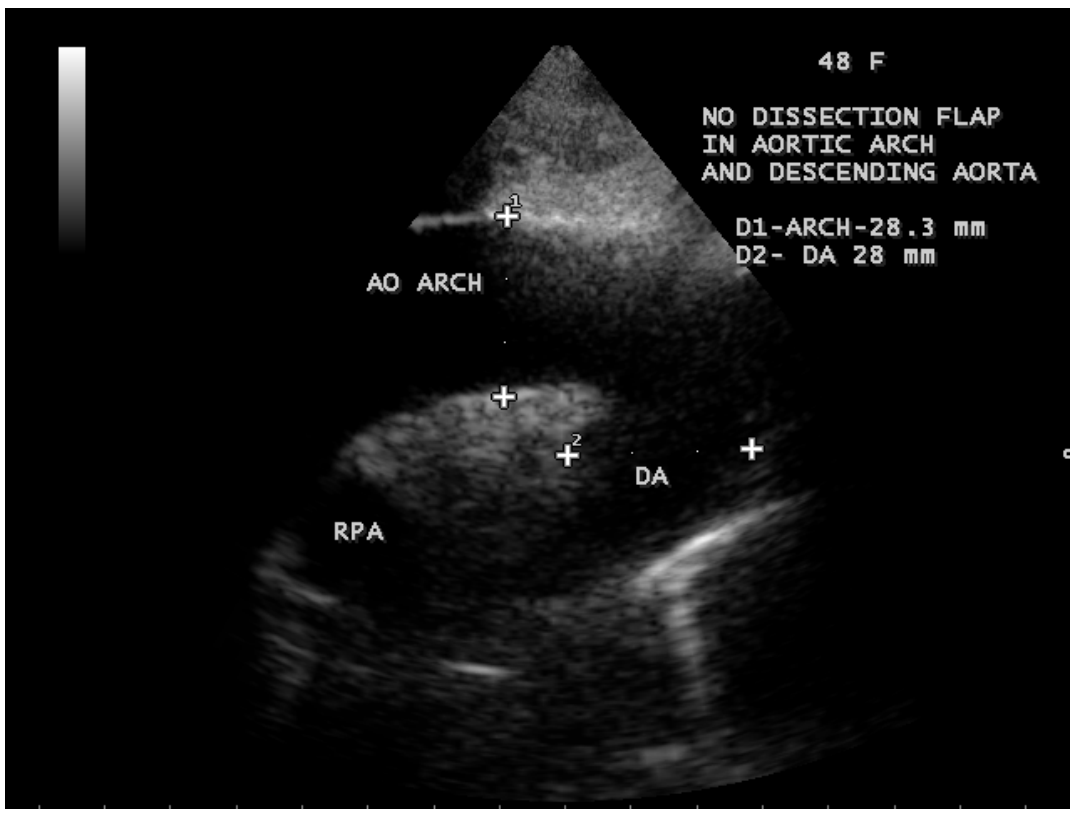

Figure 14. Suprasternal window showing the normal aortic arch. 


\subsection{Management}

Therapy for aortic dissection is directed to halt the progress of dissection process since lethal complications may arise from the the intimal tear and its subsequent course may result in vascular compromise or aortic rupture [74].

\subsection{Medical Therapy}

Since the arterial $\mathrm{d} P / \mathrm{d} t$ reflects the force of $\mathrm{LV}$ ejection and it is the major stress acting on the aortic wall that contributes to both genesis and subsequent propagation of dissection, its diminution and reduction of systolic blood pressure are the two primary goals of pharmacological therapy. Acute dissection generally presents as a hypertensive emergency and the prime consideration of medical management is to maintain the mean arterial pressure around 60 to $75 \mathrm{mmHg}$ and the systolic blood pressure to be reduced to values between 100 and $120 \mathrm{mmHg}$ with an initial decrease should be at 20\% [75]. Historically, Wheat et al. [76] first introduced the aggressive drug therapy for aortic dissection by originally using reserpine and guanethidine. A combination of beta blocker and a vasodilator (sodium nitroprusside) remains as a standard medical therapy recently. To reduce the $\mathrm{d} P / \mathrm{d} t$, an intravenous beta blocker, preferably propranolol $1 \mathrm{mg}$ every 3 to 5 minutes $(0.15 \mathrm{mg} / \mathrm{kg})$ until a satisfactory beta blockade (heart rate 60 to 80 beats/minute) up to a total dose of 2 to $6 \mathrm{mg}$ and then at 4 to 6 hours interval to maintain the adequate heat rate. In patients with labile arterial pressure or obstructive pulmonary disease, an ultra-short-acting beta blocker esmolol 500 $\mathrm{mcg} / \mathrm{kg}$ IV bolus, followed by continuous infusion at a rate of $50 \mathrm{mcg} / \mathrm{kg} / \mathrm{minute}$ and titrated up to $200 \mathrm{mcg} / \mathrm{kg} /$ minute is useful especially if surgery is to be planned. Labetalol, an alpha and beta adrenergic receptor antagonist is an alternative drug to lower both $\mathrm{d} P / \mathrm{d} t$ and arterial pressure. It is given in an initial dose $20 \mathrm{mg}$ IV over 2 minutes period, followed by 40 to $80 \mathrm{mg}$ every 10 to 15 minutes until the heart rate and blood pressure have been controlled and then a maintenance dose of $2 \mathrm{mg} /$ minute.

The most appropriate drug to provide pain relief is an opiate, the IV morphine sulphate. It reduces the force of cardiac contraction and the rate of rise of aortic pressure $(\mathrm{d} P / \mathrm{d} t)$, retards propagation of dissection; delays rupture and also prevent exacerbation of tachycardia and hypertension. AHA (American Heart Association) guidelines recommend beta blocker as a first-line treatment. Vasodilators should be given if systolic blood pressure $>120 \mathrm{mmHg}$ after beta blocker therapy and pain control. Appropriate rate control medications are mandatory before the initiation of vasodilator therapy as they induce reflex tachycardia and worsen the stress on the arterial wall. Calcium channel blockers and angiotensin converting enzyme (ACE) inhibitors are the acceptable alternatives in patients with contraindications to beta blockers. In refractory hypertension (persistent hypertension on the maximum dose of three different classes of antihypertensive drugs), an involvement of renal arteries with release of large amount of renin should be considered. In this setting, the most effective agent is IV ACE inhibitor, the enalaprilat given in an initial dose of $0.625 \mathrm{mg}$ every 4 to 6 hours to con- 
trol the blood pressure. Sublingual nifedipine is also successful to treat refractory hypertension associated with aortic dissection [77]. The efficacy of trimethaphan, a ganglionic blocker and a direct vasodilator is less predictable and it may cause tachyphylaxis, severe hypotension, urinary retention, and ileus. Hydralazine and minoxidil should be avoided since they produce a hyperdynamic response that would increase the $\mathrm{d} P / \mathrm{d} t$.

The potential problems encountered during medical therapy could be extension of dissection, aortic rupture and organ malperfusion resulting in hypotension and shock. In such cases attempts must be done to stabilize the patient with medical therapy which includes volume expansion with crystalloids and vasopressors (norepinephrine and phenylephrine) to titrate the mean arterial pressure at $70 \mathrm{mmHg}$. The extreme aggressive attempts at doing so may result in further propagation of false lumen [78] with adverse outcome, the aortic insufficiency and pericardial tamponade since both conditions are preload-dependent [79]. Therefore, treatment of shock associated with aortic dissection should be managed by rapid surgical intervention.

If coronary insufficiency occurs, nitrates may be used, but therapy with thrombolytic agents and aspirin should be avoided.

\subsection{Surgical Therapy}

The principal aim of cardiac surgery in type A aortic dissection is to obliterate the entry tear in the ascending aorta, thereby preventing flow into the false lumen, encouraging thrombosis of the false lumen and healing of the aortic dissection [80]. Definitive surgical therapy was first developed by Michael E. DeBakey, Denton Cooley, and Oscar Creech, the cardiac surgeons associated with the Baylor college of medicine, Houston, Texas in 1954 [81]. DeBakey developed aortic dissection himself at the age of 97 in 2005 and underwent surgery in 2006 [82]. The fenestration procedure is the first surgical approach to aortic dissection in which the dissected aorta was incised and a distal communication was created between the true and false channels thereby decompress the false lumen. This procedure is used in selected cases of dissection involving the descending aorta to relieve the renal or mesenteric or limb ischemia [83].

When the proximal aorta is fragile or badly torn or entire root is aneurysmatic, Bentall procedure, a radical approach is used mostly, in which a composite prosthetic graft (aortic valve plus ascending aorta tubular graft, i.e., a prosthetic aortic valve sewn on to the end of a Dacron tube graft) facilitates replacement of both ascending aorta and aortic valve together and coronary arteries are reimplanted as buttons of aortic tissue into the graft wall [84] [85]. Bypass grafting of coronary arteries using saphenous vein segments is to be done when the coronary ostia were torn by the dissection.

The first successful repair of aortopulmonary fistula was reported by Giacobine and Cooley in 1960 [86]. Closure of the fistula results in immediate hemodynamic and symptomatic relief. 


\subsection{Interventional Therapy}

Endovascular stent grafts are not indicated for repair of the ascending aorta or aortic arch and it is a standard treatment in most cases of distal aortic dissection. The fenestration/stent treatment could be used in unstable proximal dissection as a palliative treatment in high surgical risk patients. There are two endovascular techniques used to manage the acute vascular complications secondary to aortic dissection as follows.

a) Percutaneous balloon fenestration of the intimal flap which involves crossing an intact intimal flap with a wire, passing a balloon-tipped catheter over the wire, and then expanding the balloon to tear a hole in the intimal flap which allows the blood to flow from the false lumen into the true lumen, thereby decompress the distended false lumen.

b) Percutaneous stenting of the affected arterial branch whose flow has been compromised by the dissection process, in which a stent is deployed within the lumen supplying the branch vessel to hold the lumen, opens by displacing the intimal flap towards and overcoming the pressure from the other lumen by a balloon fenestration procedure.

Percutaneous aortic graft stenting are currently available and shows better results than surgical graft stenting [87]. Aortic stenting is primarily used to supplement fenestration as well as to reduce the dissection flap. In high grade compression of true lumen supplying to major aortic branch, stenting may play a role to enlarge the compressed lumen and to increase the distal flow. An average stent grafts are $3.5 \mathrm{~cm}(2.4-4.5 \mathrm{~cm})$ in diameter and $10.5 \mathrm{~cm}$ (preferably $<15$ $\mathrm{cm}$ ) long. After deployment of a stent, a balloon incorporated in the system, allows further apposition of the stent struts to the wall of the true lumen and to occlude the intimal tear rather than wrapping of the intimal flaps to the wall of the false lumen. Attempting to eliminate tears and reentries starting at the beginning of the intervention may improve the prognosis. Use of candy-plug technique with an excluder aortic extender for distal occlusion of a large false lumen aneurysms in chronic aortic dissection and an Amplatzer vascular plug II as a sealing button to obliterate the false lumen have been reported recently [88], [89]. "Tear-oriented surgery" for acute Type A dissection and open stent-grafting (OSG-Frozen ${ }^{\circledR}$ Japan, Life line, Tokyo) or frozen elephant trunk (FET) [90] involves substituting "distal anastomosis to the descending aortic suture by fixation with the stent-graft" in aortic arch surgery was launched in Japanese patients in 2014 [91].

\subsection{Outcome}

The IRAD (International Registry of Acute Aortic Dissection) study reported mortality rate of $27 \%$ for type A aortic dissection in 464 patients undergone surgical therapy [92] and in experienced centers, the long-term survival rate was $>90 \%$. The Japanese association of thoracic surgery reported overall hospital mortality was $9.1 \%$ in 2013 in a study of 4444 patients with acute type A aortic dissection who underwent surgical correction. 


\subsection{Prophylactic Measures}

The accepted critical aortic root diameter of $5-5.5 \mathrm{~cm}$ at any age even in infan$\mathrm{cy}$, the prophylactic replacement of aortic root should be performed at a diameter of $5.5 \mathrm{~cm}$ and this general agreement is not applicable to other segments of the aorta. All patients should receive lifelong antihypertensive medications including beta blockers, the blood pressure should not exceed $130 \mathrm{mmHg}$ systolic for both children and adults [93] and to be titrated to $<120 / 80 \mathrm{mmHg}$.

\section{Conclusion}

Aortic dissection is the most frequent form of acute aortic syndrome and it is a serious condition that needs immediate medical and surgical care. It is relatively rare, occurring at a rate of 3 per 100,000 people per year. It often presents as a two-step process. The first event is characterized by severe pain and pulse loss and thereafter, the bleeding stops. The second event sets in when the pressure exceeds a critical limit and rupture occurs. The risk of rupture is 10 times higher in hypertensive individuals. Aortopulmonary fistula is an exceedingly rare complication of aortic dissection and only 13 cases ( 4 in acute, 8 in chronic dissections and one found during surgery of type A dissection) have been reported up to 1999. Another case of aortopulmonary fistula was reported at this hospital due to rupture of proximal aortic dissection in a 48-year-old woman in 2017. In ascending aortic dissection, $75 \%$ die within 2 weeks without surgery and so urgent immediate surgery is mandatory in Type A aortic dissection.

\section{References}

[1] Bella, J.N., MacCluer, J.W., Roman, M.J., Almasy, L., North, K.E., Welty, T.K., et al. (2002) Genetic Influences on Aortic Root Size in American Indians: The Strong Heart Study. Arteriosclerosis Thrombosis and Vascular Biology Journal, 22, 10081011. https://doi.org/10.1161/01.ATV.0000017473.78775.F6

[2] Svensson, L.G., Crawford, E.S., Coselli, J.S., Safi, H.J. and Hess, K.R. (1989) Impact of Cardiovascular Operation on Survival in the Marfan Patients. Circulation, 80, 233-242.

[3] Gillinov, A.M., Zehr, K.J., Redmond, J.M., Gott, V.L., Deitz, H.C., Reitz, B.A., Laschinger, J.C. and Cameron, D.E. (1997) Cardiac Operations in Children with Marfan's Syndrome: Indications and Results. Annals of Thoracic Surgery, 64, 1140 1144. https://doi.org/10.1016/s0003-4975(97)00849-7

[4] Sakai, L., Keene, D. and Engvall, E. (1986) Fibrillin, A New 350 kD Glycoprotein Is A Component of Extracellular Microfibrills. Journal of Cellular Biology, 103, 2499 2509. https://doi.org/10.1083/jcb.103.6.2499

[5] Collod, G., Babron, M.C., Jondeau, G., et al. (1994) A Second Locus for Marfan Syndrome Maps to Chromosome 3p24.2-p25. Nature Genetics, 8, 264-268.

https://doi.org/10.1038/ng1194-264

[6] Ramirez, F. (1996) Fibrillin Mutations in Marfan Syndrome and Related Phenotypes. Current Opinion in Genetics \& Development, 6, 309-315. https://doi.org/10.1016/S0959-437X(96)80007-4

[7] Pope, F.M., Narcisi, P., Nicholls, A.C., Germaine, D., Pals, G. and Richards, A.J. (1996) COL3A1 Mutations Cause Variable Clinical Phenotypes Including Acrogeria 
and Vascular Rupture. British Journal of Dermatology, 135, 163-181. https://doi.org/10.1111/j.1365-2133.1996.tb01143.x

[8] Larson, E.W. and Edwards, W.D. (1984) Risk Factors for Aortic Dissection: A Necropsy Study of 161 Cases. American Journal of Cardiology, 53, 849-855.

https://doi.org/10.1016/0002-9149(84)90418-1

[9] Kamalakannan, D., Rosman, H.S. and Eagle, K.A. (2007) Acute Aortic Dissection. Critical Care Clinics, 23, 779-800. https://doi.org/10.1016/j.ccc.2007.07.002

[10] Johansson, G., Markstrom, U. and Swedenborg, J. (1995) Ruptured Thoracic Aortic Aneurysms: A Study of Incidence and Mortality Rates. Journal of Vascular Surgery, 21, 985. https://doi.org/10.1016/S0741-5214(95)70227-X

[11] Eisenberg, M.J., Rice, S.A., Paraschos, A., et al. (1993) The Clinical Spectrum of Patients with Aneurysms of the Ascending Aorta. American Heart Journal, 125, 1380 1385. https://doi.org/10.1016/0002-8703(93)91011-3

[12] Fox, R., Ren, J.F., Panidis, I.P., et al. (1984) Annuloaortic Ectasia: A Clinical and Echocardiographic Study. American Journal of Cardiology, 54, 177-181. https://doi.org/10.1016/0002-9149(84)90325-4

[13] Scheck, M., Siegel, R.C., Parker, J., Chang, Y.H. and Fu, J.C. (1979) Aortic Aneurysm in Marfan's Syndrome: Changes in the Ultrastructure and Composition of Collagen. Journal of Anatomy, 129, 645-657.

[14] Braverman, A.C. (2010) Acute Aortic Dissection. Circulation, 122, 184-188. https://doi.org/10.1161/CIRCULATIONAHA.110.958975

[15] Wheat, M.W. (1987) Acute Dissection of the Aorta. Cardiovascular Clinics, 17, 241 262.

[16] Dart, A.M. and Kingwell, B.A. (2001) Pulse Pressure-A Review of Mechanisms and Clinical Relevance. Journal of American College of Cardiology, 37, 975-984. https://doi.org/10.1016/S0735-1097(01)01108-1

[17] Hagan, P.G., Nienaber, C.A., Issellbacher, E.M., et al. (2000) International Registry of Acute Aortic Dissection (IRAD). New Insights into an Old Disease. Journal of American Medical Association, 283, 897-903. https://doi.org/10.1001/jama.283.7.897

[18] De Virgilio, C., Nelson, R.J., Milliken, J., et al. (1990) Ascending Aortic Dissection in Weight Lifters with Cystic Medial Degeneration. The Annals of Thoracic Surgery, 49, 638-642. https://doi.org/10.1016/0003-4975(90)90315-W

[19] Svensson, L.G., Labib, S.B. and Eisenhau, J.R. (1999) Intimal Tear without Haematoma. Circulation, 99, 1331-1336. https://doi.org/10.1161/01.CIR.99.10.1331

[20] Daily, P.O., Trueblood, H.W., Stinson, E.B., et al. (1970) Management of Acute Aortic Dissections. Annals of Thoracic Surgery, 10, 237-247. https://doi.org/10.1016/S0003-4975(10)65594-4

[21] DeBakey, M., McCollum, C., Crawford, E., Morris, G., Howell, J. and Noon, G. (1982) Dissection and Dissecting Aneurysms of the Aorta: Twenty-Year Follow Up of Five Hundred Twenty-Seven Patients Treated Surgically. Surgery, 92, 1118-1134.

[22] Erbel, R., Alfonso, F., Boileau, C., Dirsch, O., Eber, B., Haverich, A., et al. (2001) Diagnosis and Management of Aortic Dissection. Recommendations of the Task Force on Aortic Dissection, European Society of Cardiology. European Heart Journal, 22, 1642-1681. https://doi.org/10.1053/euhj.2001.2782

[23] Criado, J. (2016) On the Death of King George II in 1760: Aortic Dissection in Perspective.

[24] Criado, F.J. (2011) Aortic Dissection: A 250-Year Perspective. Texas Heart Institute 
Journal, 38, 694-700.

[25] Nicholls, F. (1761) Observations Concerning the Body of His Late Majesty. Philosophical Transactions of the Royal Society, 52, 265-274. https://doi.org/10.1098/rstl.1761.0052

[26] Leonard, J.C. (1979) Thomas Bevill Peacock and the Early History of Dissecting Aneurysm. British Medical Journal, 2, 260-262. https://doi.org/10.1136/bmj.2.6184.260

[27] Boyd, L.J. (1924) A Study of Four Thousand Reported Cases of Aneurysm of the Thoracic Aorta. American Journal of Medical Sciences, 108, 654-668. https://doi.org/10.1097/00000441-192411000-00006

[28] Bory, M., Donnarel, G., Djiane, P., Dor, V. and Serradimigni, A. (1970) Dissection Aortiquerompuedans I'arterepulmunaire chez un malade atteint d'hypercholesterolemie familial. Archives des Maladies du Coeur et des Vaisseaux Journal, 8, 11971204.

[29] McCarthy, C., Dickson, G.H., Besterman, E.M.M., Bromley, L.L. and Thompson, A.E. (1972) Aortic Dissection, with Rupture through Ductus Arteriosus into Pulmonary Artery. British Heart Journal, 34, 428-430. https://doi.org/10.1136/hrt.34.4.428

[30] Spier, L.N., Hall, M.H., Nelson, R.L., Parnell, V.A., Pogo, G.J. and Tortolani, A.J. (1995) Aortic Dissection: Rupture into Right Ventricle and Right Pulmonary Artery. Annals of Thoracic Surgery, 59, 1017-1019. https://doi.org/10.1016/0003-4975(94)00740-X

[31] Atay, Y., Can, L., Yagdi, T. and Buket, S. (1998) Aortopulmonary Artery Fistula, Presenting With Congestive Heart Failure in a Patient with Aortic Dissection. Texas Heart Institute Journal, 25, 72-74.

[32] Marco Piciche, M.D., Ruggero De Paulis, M.D. and Luigi Chiariello, M.D. (1999) A Review of Aortopulmonary Fistulas in Aortic Dissection. Annals of Thoracic Surgery, 68, 1833-1836.

[33] Laurent, S., Cockcroft, J., VanBortel, L., Boutouyrie, P., Giannattasio, C., Hayoz, D., et al. (2006) European Network for Non-Invasive Investigations of Large Arteries. Expert Consensus Document on Arterial Stiffness: Methodological Issues and Clinical Applications. European Heart Journal, 27, 2588-2605. https://doi.org/10.1093/eurheartj/ehl254

[34] Braunwald, E. (1980) Heart Disease. W.B. Saunders, Philadelphia, 1602.

[35] Vriz, O., Driussi, C., Bettio, M., et al. (2013) Aortic Root Dimensions and Stiffness in Healthy Subjects. American Journal of Cardiology, 112, 1224-1229. https://doi.org/10.1016/j.amjcard.2013.05.068

[36] Vilacosta, I. and SanRoman, J.A. (2001) Acute Aortic Syndrome. Heart, 85, 365368. https://doi.org/10.1136/heart.85.4.365

[37] Wilson, S.K. and Hutchins, G.M. (1982) Aortic Dissecting Aneurysms: Causative Factors in 204 Subjects. Archives of Pathology \& Laboratory Medicine, 106, 175 180.

[38] Choi, S.H., Choi, S.J., Kim, J.H., et al. (2001) Useful CT Findings for Predicting the Progression of Aortic Intramural Hematoma to Overt Aortic Dissection. Journal of Computer Assisted Tomography, 25, 295-299. https://doi.org/10.1097/00004728-200103000-00025

[39] Ouint, L.E., Williams, D.M., Francis, I.R., et al. (2001) Ulcer-Like Lesions of the Aorta: Imaging Features and Natural History. Radiology, 218, 719-723. https://doi.org/10.1148/radiology.218.3.r01mr24719 
[40] Hayashi, H., Matsuoka, Y., Sakamoto, I., et al. (2000) Penetrating Atherosclerotic Ulcer of the Aorta: Imaging Features and Disease Concept. Radio Graphics, 20, 9951005. https://doi.org/10.1148/radiographics.20.4.g00j101995

[41] Coady, M., Rizzo, J. and Elefteriades, J. (1999) Pathologic Variants of Thoracic Aortic Dissections. Penetrating Atherosclerotic Ulcers and Intramural Hematomas. Cardiology Clinics of North America, 17, 637-657.

[42] Harris, J.A., Bis, K.G., Glover, J.L., et al. (1994) Penetrating Atherosclerotic Ulcers of the Aorta. Journal of Vascular Surgery, 19, 90-98. https://doi.org/10.1016/S0741-5214(94)70124-5

[43] Song, J.K., Kim, H.S., Kang, D.H., et al. (2001) Different Clinical Features of Aortic Intramural Hematoma versus Dissection Involving the Ascending Aorta. Journal of American College of Cardiology, 37, 1604-1610. https://doi.org/10.1016/S0735-1097(01)01184-6

[44] Mohr-Kahaly, S., Erbel, R., Rennollet, H., et al. (1989) Ambulatory Follow-Up of Aortic Dissection by Transesophageal, Two-Dimensional and Color Coded Doppler Echocardiography. Circulation, 80, 24-33. https://doi.org/10.1161/01.CIR.80.1.24

[45] JCS (Joint Working Group) (2013) Guidelines for Diagnosis and Treatment of Aortic Aneurysm and Aortic Dissection (JCS 2011): Digest Version. Circulation Journal, 77, 789-828. https://doi.org/10.1253/circj.CJ-66-0057

[46] Von Koloditsch, Y., Schwartz, A.G. and Nienaber, C.A. (2000) Clinical Prediction of Acute Aortic Dissection. Archives of Internal Medicine, 160, 2977-2982. https://doi.org/10.1001/archinte.160.19.2977

[47] Spittel, P.C., Spittel, J.A., Joyce, J.W., et al. (1993) Clinical Features and Differential Diagnosis of Aortic Dissection: Experience with 236 Cases (1980 through 1990). Mayo Clinic Proceedings, 68, 642. https://doi.org/10.1016/S0025-6196(12)60599-0

[48] Meszaros, I., Morocz, J., Szlavi, J., et al. (2000) Epidemiology and Clinicopathology of Aortic Dissection. Chest, 117, 1271-1278. https://doi.org/10.1378/chest.117.5.1271

[49] Upadhye, S. and Schiff, K. (2012) Acute Aortic Dissection in the Emergency Department: Diagnostic Challenges and Evidence Based Management. Emergency Medicine Clinics of North America, 30, 307-327. https://doi.org/10.1016/j.emc.2011.12.001

[50] Tolenaar, J.L., Hutchison, S.J., Montgomery, D., et al. (2013) Painless Type B Aortic Dissection: Insights from the International Registry of Acute Aortic Dissection. Aorta, 1, 96-101. https://doi.org/10.12945/j.aorta.2013.13-014

[51] Nissim, J.A. (1946) Dissecting Aneurysm of Aorta: A New Sign. British Heart Journal, 8, 203-206. https://doi.org/10.1136/hrt.8.4.203

[52] Rahmatullah, S.I., Khan, I.A., Caccavo, N.D., et al. (1999) Painless Limited Dissection of the Ascending Aorta Presenting with Aortic Valve Regurgitation. Journal of Emergency Medicine, 17, 700-701.

[53] Hennessy, T.G., Smith, D., McCann, H.A., et al. (1996) Thoracic Aortic Dissection or Aneurysm: Clinical Presentation, Diagnostic Imaging and Initial Management in a Tertiary Referral Center. Irish Journal of Medical Science, 165, 259-262. https://doi.org/10.1007/BF02943084

[54] Feigenbaum, H., Armstrong, W.F. and Ryan, T. (2005) Echocardiography in Systemic Diseases and Clinical Problem Solving. In: Feigenbaum, H., Armstrong, W.F. and Ryan, T., Eds., Feigenbaum's Echocardiography, 6th Edition, Chapter 22, Lippincott Williams \& Wilkins, Philadelphia, 741.

[55] Veyssier-Belot, C., Cohen, A., Rougemont, D., et al. (1993) Cerebral Infarction Due 
to Painless Thoracic Aorta and Common Carotid Artery Dissection. Stroke, 24, 2111-2113. https://doi.org/10.1161/01.STR.24.12.2111

[56] Massetti, M., Babatasi, G., Saloux, E., et al. (1997) Aorto-Pulmonary Fistula: A Rare Event in the Evolution of a Dissecting Aneurysm of the Thoracic Aorta. European Journal of Cardiovascular Surgery, 11, 994-996. https://doi.org/10.1016/S1010-7940(96)01141-4

[57] Suzuki, T., Katoh, H., Watanabe, M., et al. (1996) Novel Biochemical Diagnostic Method for Aortic Dissection: Results of a Prospective Study Using an Immunoassay of Smooth Muscle Myosin Heavy Chain. Circulation, 93, 1244-1249. https://doi.org/10.1161/01.CIR.93.6.1244

[58] Shimony, A., Filion, K.B., Mottillo, S., Dourian, T. and Eisenberg, M.J. (2011) MetaAnalysis of Usefulness of D-Dimer to Diagnose Acute Aortic Dissection. The American Journal of Cardiology, 107, 1227-1234. https://doi.org/10.1016/j.amjcard.2010.12.027

[59] Bruce, M.L. (2013) An Evidence Based Approach to Acute Aortic Syndrome. Emergency Medicine Practice, 15, 1-23.

[60] Kamp, T.J., Goldschmidt-Clermont, P.J., Brinker, J.A. and Resar, J.R. (1994) Myocardial Infarction, Aortic Dissection, and Thrombolytic Therapy. American Heart Journal, 128, 1234-1237. https://doi.org/10.1016/0002-8703(94)90756-0

[61] Ritter Rules (2016) Thoracic Aortic Disease Coalition.

[62] Meredith, E.L. and Masani, N.D. (2009) Echocardiography in the Emergency Assessment of Acute Aortic Syndrome. European Journal of Echocardiography, 10, 131-139. https://doi.org/10.1093/ejechocard/jen251

[63] Kim, Y.W., Park, Y.-J. and Kim, D.-K. (2015) Optimal Imaging for Aortic Dissection. Endovascular Today, November 5.

[64] Lindsay, J. and Hurst, W.J. (1967) Clinical Features and Prognosis in Dissecting Aneurysm of Aorta. Circulation, 35, 880-888. https://doi.org/10.1161/01.CIR.35.5.880

[65] Erbel, R., Engberding, R., Daniel, W., Roelandt, J., Visser, C.M. and Rennollet, H. (1989) Echocardiography in Diagnosis of Aortic Dissection. The Lancet, 1, 457-461. https://doi.org/10.1016/S0140-6736(89)91364-0

[66] Come, P.C., Bivas, N.K., Sacks, B., Thurer, R.L., Weintraub, R.M. and Axelrod, P. (1984) Unusual Echocardiographic Findings in Aortic Dissection: Diastolic Prolapse of Intimal Flap into Left Ventricle. American Heart Journal, 107, 790-792. https://doi.org/10.1016/0002-8703(84)90334-X

[67] Iliceto, S., Ettore, G., Francioso, G., Antonelli, G., Biasco, G. and Rizzon, P. (1984) Diagnosis of Aneurysm of the Thoracic Aorta: Comparison between Two Noninvasive Techniques. Two-Dimensional Echocardiography and Computed Tomography. European Heart Journal, 5, 545. https://doi.org/10.1093/oxfordjournals.eurheartj.a061704

[68] Roudaut, R., Billes, M.A., Gateau, P., Besse, P. and Dallocchio, M. (1981) Two-Dimensional Echocardiography in the Diagnosis of Aortic Dissection in 41 Patients. Circulation, 64, 314.

[69] Granato, J.E., Dee, P. and Gibson, R.S. (1985) Utility of Two-Dimensional Echocardiography in Suspected Ascending Aorta Dissection. American Journal of Cardiology, 56, 124. https://doi.org/10.1016/0002-9149(85)90579-X

[70] Ferrier, A., Guertet, P., Farcot, J.C., Dubourg, O., Terdjman, M., Bardet, J. and Bourdarias, J.P. (1983) Significance of Mobile Intimal Flap in Aortic Dissection Elucidated by Echocardiography. Circulation, 68, 282. 
[71] Smuckler, A.L., Nomeir, A.M., Watts, L.E. and Hackshaw, B.T. (1982) Echocardiographic Diagnosis of Aortic Root Dissection by M-Mode and Two-Dimensional Techniques. American Heart Journal, 103, 897. https://doi.org/10.1016/0002-8703(82)90405-7

[72] Williams, D.M., Joshi, A., Dake, M.D., et al. (1994) Aortic Cobwebs: An Anatomic Marker Identifying the False Lumen in Aortic Dissection-Imaging and Pathologic Correlation. Radiology, 190, 167-174. https://doi.org/10.1148/radiology.190.1.8259399

[73] Roudaut, R.P., Billes, P., Gosse, C., Deville, E., Baudet, F., Fontan, P., Besse, H., Bricaud, M. and Dallocchio, M.D. (1988) Accuracy of M-Mode and Two-Dimensional Echocardiography in the Diagnosis of Aortic Dissection: An Experience with 128 Cases. Clinical Cardiology, 11, 553-562. https://doi.org/10.1002/clc.4960110809

[74] Armstrong, W.F., Bach, D.S., Carey, L.M., et al. (1998) Clinical and Echocardiographic Findings in Patients with Suspected Acute Aortic Dissection. American Heart Journal, 136, 1051. https://doi.org/10.1016/S0002-8703(98)70162-0

[75] White, A., Broder, J., Mando-Vandrick, J., Wendell, J. and Growe, J. (2013) Acute Aortic Emergencies-Part 2: Aortic Dissections. Advanced Emergency Nursing Journal, 35, 28-52. https://doi.org/10.1097/TME.0b013e31827145d0

[76] Wheat, M.W., Palmer, R.F., Bartley, T.D., et al. (1965) Treatment of Dissecting Aneurysms of Aorta without Surgery. Thoracic \& Cardiovascular Surgery, 50, 364373.

[77] John, M., Wiesenfarth, B. and Brenner, E. (2016) Acute Aortic Dissection. Medscape Updated December 11.

[78] Hiratzaka, L.F., Bakris, G.L., Beckman, J.A., et al. (2010) Guidelines for the Diagnosis and Management of Patients with Thoracic Aortic Disease. Circulation, 121, e266-e369.

[79] Diercks, D.B., Promes, S.B., Schuur, J.D., et al. (2015) Clinical Policy: Critical Issues in the Evaluation and Management of Adult Patients with Suspected Acute Nontraumatic Aortic Dissection. Annals of Emergency Medicine, 65, 32-42. https://doi.org/10.1016/j.annemergmed.2014.11.002

[80] Erbel, R., Oelert, H., Meyer, J., Puth, M., Mohr-Kahaly, S., Hausmann, D., et al. (1993) Effect of Medical and Surgical Therapy on Aortic Dissection Evaluated by Transesophageal Echocardiography. Implications for Prognosis and Therapy. Circulation, 87, 1604-1615. https://doi.org/10.1161/01.CIR.87.5.1604

[81] DeBakey, M.E., Cooley, D.A. and Creech, O. (1955) Surgical Considerations of Dissecting Aneurysms of the Aorta. Annals of Surgery, 142, 586. https://doi.org/10.1097/00000658-195510000-00005

[82] Altman, L.K. (2013) The Man on the Table Devised The Surgery. New York Times, Retrieved 05, 27.

[83] Elefteriades, J.A., Hartleroad, J., Gusberg, R.J., et al. (1992) Long-Term Experience with Descending Aortic Dissection. The Complication-Specific Approach. Annals of Thoracic Surgery, 53, 11. https://doi.org/10.1016/0003-4975(92)90752-P

[84] Kouchoukos, N.T., Wareing, T.H., Murphy, S.F. and Perrillo, J.B. (1991) SixteenYear Experience with Aortic Root Replacement. Results in 172 Operations. Annals of Surgery, 214, 308-318. https://doi.org/10.1097/00000658-199109000-00013

[85] Gott, V.L., Cameron, D.E., Pyeritz, R.E., et al. (1994) Composite Graft Repair of Marfan Aneurysm of the Ascending Aorta: Results in 150 Patients. Journal of Cardiac Surgery, 9, 482-489. https://doi.org/10.1111/j.1540-8191.1994.tb00880.x

[86] Giacobine, J.W. and Cooley, D.A. (1960) Surgical Treatment of Aorto-Pulmonary 
Fistula Secondary to Aortic Arch Aneurysm. Report of Successful Case. Journal of Thoracic and Cardiovascular Surgery, 39, 130-136.

[87] Nienaber, C.A., Fattori, R., Lund, G., et al. (1999) NonSurgical Reconstruction of Thoracic Aortic Dissection by Stent-Graft Placement. New England Journal of Medicine, 340, 1539-1545. https://doi.org/10.1056/NEJM199905203402003

[88] Ogawa, Y., Nishimaki, H., Chiba, K., Murakami, K., Sakurai, Y., Fujiwara, K., et al. (2016) Candy-Plug Technique Using an Excluder Aortic Extender for Distal Occlusion of a Large False Lumen Aneurysm in Chronic Aortic Dissection. Journal of Endovascular Therapy, 23, 483-486. https://doi.org/10.1177/1526602816640523

[89] Falkenberg, M., Roos, H., Lepore, V., Svensson, G., Zachrisson, K., Henrickson, O., et al. (2016) Endovascular Closure of Chronic Dissection Entries in the Aortic Arch Using the Amplatzer Vascular Plug II as a Sealing Button. Journal of Endovascular Therapy, 23, 378-383. https://doi.org/10.1177/1526602816632351

[90] Kato, M., Matsuda, T., Kaneko, M., et al. (1998) Outcomes of Stent-Graft Treatment of False Lumen in Aortic Dissection. Circulation, 98, 305-311.

[91] Yutaka, O. (2016) Current Surgical Results of Acute Type A Aortic Dissection in Japan. Annals of Cardiothoracic Surgery, 5, 368-376. https://doi.org/10.21037/acs.2016.06.02

[92] Eagle, K.A., Brukmann, D., Isselbacher, E., et al. (2000) Predictive of Mortality in Patients with Type A Acute Aortic Dissection-Results from the International Registry of Acute Aortic Dissection (IRAD). Journal of American College of Cardiology, 35, 323.

[93] Braverman, A.C. (1998) Exercise and the Marfan Syndrome. Medicine \& Science in Sports \& Exercise, 30, 387-395. https://doi.org/10.1097/00005768-199810001-00007

Submit or recommend next manuscript to SCIRP and we will provide best service for you:

Accepting pre-submission inquiries through Email, Facebook, LinkedIn, Twitter, etc. A wide selection of journals (inclusive of 9 subjects, more than 200 journals)

Providing 24-hour high-quality service

User-friendly online submission system

Fair and swift peer-review system

Efficient typesetting and proofreading procedure

Display of the result of downloads and visits, as well as the number of cited articles

Maximum dissemination of your research work

Submit your manuscript at: http://papersubmission.scirp.org/

Or contact crcm@scirp.org 